\title{
A Brief Look at Human Impacts on Sharks
}

\begin{abstract}
This brief review examines the many human activities that threaten sharks, their impacts, and the implications for the ecosystems that rely upon these apex predators. As keystone species, sharks play a crucial role in maintaining healthy ecosystems by asserting top-down forces on trophic webs and keeping prey populations healthy and in balance. However, sharks' slow growth rates, low fecundity and late sexual maturity means they are highly vulnerable to human impacts. Here the author looks at some human practices, including overfishing, shark finning, and lethal management programs designed to keep bathers safe. Examples of the detrimental and sometimes catastrophic effects of these practices are also examined and a brief commentary of the current trends in attitudes and efforts towards shark conservation is undertaken.
\end{abstract}

Volume 5 Issue 4 - 2017

\author{
Jessica Strickland \\ I.SEA. Conservation, UK
}

Correspondence: Jessica Strickland, I.SEA. Conservation, UK, Email jess@iseaconservation.org

Received: March 30, 2017| Published: April 05, 2017

\section{Review}

Sharks are top-level predators that play an important role in maintaining healthy marine ecosystems and that are highly vulnerable to population declines as a result of human impacts. As apex predators, sharks inflict strong top-down forces on trophic webs, keep lower order predator populations under control and prevent ecosystem unbalance. ${ }^{1}$ However, their slow growth rates, low fecundity and late sexual maturity make them highly sensitive to overexploitation. ${ }^{2}$ Humans have fished sharks for thousands of years but the past decade has seen detrimental, often catastrophic, effects on shark populations all around the globe. ${ }^{2}$ Humans have primarily impacted upon sharks through overfishing, finning and certain shark management programs, which are designed to keep bathers safe from shark attacks. ${ }^{1}$ This review will explore the detail of human impacts on sharks and their effects on various shark populations around the world.

Sharks are fishes that are classified within the super order Selachimorpha that, with the rays and skates, make up the class Chondrichtheys. ${ }^{3}$ They have five to seven gill slits, a cartilaginous skeleton and a body covered with dermal denticles. ${ }^{3}$ There are over 470 species of sharks, ranging in size from the dwarf lantern shark (17 centimeters) to the whale shark, which is the largest fish in the ocean and can be 12 meters long. ${ }^{3,4}$ Sharks tend to be apex predators and play an important role in marine trophic webs, exerting top-down forces, shaping marine communities and maintaining ecosystem balance. ${ }^{1}$ There are many examples within the literature of cases where this balance has been thrown out by human impacts, and the tropic cascading effects have been drastic. ${ }^{1}$ For example, overfishing of large pelagic sharks in the North Atlantic led to an exponential increase in the number of rays, which fed on bay scallops..$^{5}$ The scallop fishery, which had been sustainable up until that point, collapsed, adversely impacting the local economy. ${ }^{5}$

Sharks are highly vulnerable to human impacts and population declines due to aspects of their life histories. ${ }^{1}$ Of all vertebrates, they are some of the latest to reach sexual maturity and have slow reproduction rates. ${ }^{2}$ They also have long gestation periods and as a result have relatively low fecundity. ${ }^{2}$ As Dulvy et al. ${ }^{2}$ point out, these characteristics of sharks result in very low population growth rates and weak density-dependent compensation in juvenile survival. Naturally this makes them highly vulnerable and sensitive to human impacts, which can decrease of the abundance of sharks. ${ }^{2}$

Humans have caused significant declines in many shark populations around the world, with 27 species listed as critically endangered or endangered on the International Union for Conservation of Nature and Natural Resources (IUCN) Red List. ${ }^{6}$ A recent study suggests that $15 \%$ of shark species are threatened and sharks are extremely vulnerable to overexploitation. ${ }^{2}$ Throughout history, human impacts on sharks have tended to be concentrated in coastal ecosystems. However, with today's technologies, there are few populations of sharks that are inaccessible and therefore unaffected by humans. ${ }^{1}$

Shark fishing dates back to before recorded history and humans have, at different points in time, found uses for all of their body parts. ${ }^{7}$ However, they only began to have high commercial value in fairly recent times, so long-term fisheries records do not exist. ${ }^{8}$ This has made it difficult to establish accurate estimates of the total long-term impacts of fishing on shark populations. However, current estimates suggest that between 63 and 273 millions sharks are killed annually, ${ }^{9}$ and even in the fairly short-term records that have been kept, significant declines have been observed across almost all fished shark populations. ${ }^{1}$ In fact, sharks have been found to be so vulnerable that overexploitation can happen even with low levels of fishing taking place. ${ }^{10}$ It has also been suggested that shark populations can take decades to recover once a decline has occurred..$^{11}$ Dulvy et al..$^{12}$ found that $75 \%$ of the world's pelagic sharks and rays have a heightened risk of extinction as a result of overfishing. Despite this, exploitation is common around the world and fishing can include large-scale industrial and commercial fishing; small-scale traditional, recreational or artisanal subsistence fishing; and as bycatch in other fisheries. ${ }^{1}$

In a study of pelagic sharks in the Gulf of Mexico, the impacts of industrial fishing have caused drastic declines in shark abundances as well as shifts in shark sizes. ${ }^{13}$ They found that the shark species that were originally most common experienced the most significant declines. ${ }^{13}$ Between the 1950s and 1990s, the abundance of oceanic white tips (Carcharhinus longimanus) experienced a $>99 \%$ decline, silky shark (Carcharhinus falciformis) populations declined by $91 \%$ and dusky sharks (Carcharhinus obscurus) by $79 \% .{ }^{13}$ Additionally, on overfished populations, decreased mean sizes are usually a result of targeted fishing pressure on larger individuals. This was found to be the case in this study in the Gulf of Mexico, where the mean size of individuals within populations of different shark species was at or below the size at which that species reaches sexual maturity. ${ }^{13}$ This is likely to fast-track shark declines as future generations of sharks are being extinguished before their parents have reached maturity and reproduced. There are many example of how large-scale fishing operations have declined shark populations but this isn't the only type of fishing that can unsustainably impact on vulnerable shark populations. 
Smaller scale fishing practices, such as traditional, recreational and artisanal fishing, can also cause localised depletions of shark populations, generally in coastal and in-shore waters. ${ }^{7}$ Traditional shark fishing has been undertaken for thousands of years using spears, canoes, and simple hooks by the Aborigines in Australia ${ }^{14}$ the Maoris in New Zealand, ${ }^{15}$ the Polynesians, Micronesians and Melanesians ${ }^{16}$ and throughout many other parts of the world. Traditional fishing is limited to shallow coastal waters and generally has very minor impacts on sharks. ${ }^{7}$ Recreational fishing also takes place in coastal waters, but current technologies and trends see recreational fishers being able to reach deeper seas and cover more ground. ${ }^{7}$ Generally pelagic sharks are targeted and, although extensive studies are limited for this type of fishing, general declines in catch rates have been observed. ${ }^{1}$ Artisanal fisheries and their impacts vary between locations and target species are generally not reported but Walker ${ }^{7}$ argues that, "it is likely that artisanal fisheries have caused declines in the abundance of a number of species of shark in inshore and coastal waters.

Commercial fishing for other fisheries results in millions of sharks being caught as bycatch each year and estimates suggest that over half of the sharks caught and killed are bycatch. ${ }^{1}$ It is difficult to make these estimations because, in most countries, there are nonexistent or ineffective regulations on reporting bycatch. ${ }^{12}$ Even in those fisheries that do report bycatch, the species, sex and size of the bycatch often goes unrecorded and this puts these populations at high risk of becoming depleted before scientists even realise this decline is happening. ${ }^{7}$ Longline fishing is particularly notorious for catching unwanted sharks, but purse seine, gillnet and other trawling fisheries are also to blame. ${ }^{12}$ Generally, the fishery is targeting more profitable tuna, swordfish, billfish or small pelagic fish but sharks die in the process. ${ }^{17}$ However, the growing economic value of shark fins has caused a dramatic increase in fisheries specifically targeting sharks for their fins. ${ }^{18}$

Shark fins have become highly valuable due to an increased demand for shark fin soup, considered to be a delicacy in many growing Asian countries. ${ }^{19}$ Typically, shark fins are worth more than the rest of the meat and it is profitable for fishers to keep only the shark fins and dispose of the rest of the body at sea. ${ }^{2}$ The shark often drowns, as it is unable to swim and therefore unable to keep oxygenated water moving over its gills. It has been estimated that an annual average of 38 million sharks are being caught for the shark fin trade. ${ }^{8}$ Shark finning is highly controversial and has been banned in many regions.

Fishing and finning aren't the only reasons sharks are killed by humans. Globally, many different shark control methods have been adopted to minimize the risk of human and shark interactions along populated coastlines, including culls using nets and drumlins. ${ }^{20}$ These efforts seek to reduce the local abundance of large, potentially dangerous sharks such as white sharks (Carcharodon carcharias), tiger sharks (Galeocerdo cuvier) and bull sharks (Carcharhinus leucas), decreasing the probability of a shark attack (Dudley 1997). These measures have been very effective in reducing shark attacks but are heavily criticized for their impacts on the marine ecosystem. The main criticism is the fact that they are incredibly unselective in the animals that they catch. ${ }^{21}$

Shark nets often entangle lots of bycatch, such as turtles, dolphins, dugongs, whales, rays and other sharks, many of which are threatened or protected species. ${ }^{20}$ In Queensland, Australia, there are around 35 nets and 348 drumlines in use in populated areas along a $1,760 \mathrm{~km}$ stretch of the coast. ${ }^{20}$ The Queensland Government has kept records of what the nets catch and so trends can be observed. The same is the case for New South Wales in Australia, where a protective shark meshing program was introduced in 1937 (Dudley 1997). Both programs have been criticised for the bycatch that they entangle, however, some studies of the catch records of each have suggested that the total numbers of individuals of each species that are caught as bycatch are insignificant and are not likely to have detrimental effects on those populations. ${ }^{22,23}$ Shark control programs also receive criticism for causing declines in shark populations.

For example, a shark netting program near Durban in South Africa showed significant declines in the number of sharks caught per unit effort. A study found that the shark populations that experienced the most alarming declines were those that were originally there in the greatest abundance. ${ }^{24}$ Between 1961-1972 certain species' catch rates declined between $27 \%$ and $>99 \% .{ }^{24}$ A similar study of the Queensland program indicated that certain shark species have also seen a significant population decrease..$^{23}$ These sorts of studies, as well as an increased understanding of the importance and vulnerability of many shark populations, have fuelled the growing movement against the use of shark nets. ${ }^{25}$ The investigation and trial use of non-lethal shark prevention methods has been growing. ${ }^{25}$

One example of where a non-lethal alternative to traditional shark prevention programs was found to be incredibly successful in Recife, in Brazil. ${ }^{26}$ The program used long lines and baited drumlines to catch potentially dangerous sharks, which were then relocated and released and tended to swim away from protected beaches. ${ }^{26}$ An additional benefit was that the mortality rate of bycatch was a lot lower than conventional shark nets. ${ }^{26}$ Hazin \& Afonso ${ }^{26}$ found that, over a fouryear period, the program was not only better for the marine ecosystem but also reduced shark attacks by $97 \%$, which is greater than netting programs that tend to reduce attacks by around $88-91 \%$ (Dudley 1997). One might argue that this system is only a small step down from the usual system of lethal baited drumlines that are used along many coasts around the world.

Scientific research, as well as a growing understanding of sharks, has led to an increased focus on conservation and greater efforts to manage the above-described impacts. There are efforts underway to identify and protect shark biodiversity hotspots ${ }^{27,2}$ increase international and regional level regulations ${ }^{28,29}$ decrease harmful fishing impacts; ${ }^{30}$ increase and improve catch reporting; eliminate shark finning ${ }^{31}$ and improve shark control programs. ${ }^{26}$ Despite this, there is still a long way to go, and it is predicted that the world will see a number of extinctions before appropriate action is taken to eliminate the human threats to sharks and reduce fishing to sustainable levels. ${ }^{2}$

This review has explored the many impacts that sharks face at the hands of humans. Overfishing, finning, shark control programs and inadequate management of the human threats to sharks have caused significant population declines around the world. Many of these declines are drastic, such as the example in the Gulf of Mexico, where a catastrophic decrease in the abundance of four common shark species due to overfishing occurred, and in Durban, South Africa, where a shark netting program had similar effects. However, shark conservation efforts are on the rise as a result of the increased awareness around the importance and vulnerability of these apex predators that are so crucial to maintaining healthy, balanced marine ecosystems. ${ }^{32}$

\section{Acknowledgments}

None. 


\section{Conflicts of interest}

None.

\section{References}

1. Ferretti F, Worm B, Britten GL, et al. Patterns and ecosystem consequences of shark declines in the ocean. Ecology Letters. 2010;13(8):1055-1071

2. Dulvy NK, Fowler SL, Musick JA, et al. Extinction risk and conservation of the world's sharks and rays. Elife. 2014;3:e590.

3. Gilbert PW. Biology and behaviour of sharks. Endeavour 1984;8(4):179-187.

4. Springer S, Burgess GH. Two new dwarf dogsharks (Etmopterus, Squalidae) found off the Caribbean Coast of Colombia. Copeia. 1985 ;(3):584-591.

5. Fegley SR, Gaskill DW, Geraldi NR, et al. Enhancing the potential for population recovery: Restoration options for bay scallop populations, Argopecten irradians concentricus, in North Carolina. Journal of Shellfish Research. 2009;28(3):477-489.

6. IUCN (International Union for Conservation of Nature and Natural Resources). The IUCN Red List of Threatened Species (online). 2017

7. Walker TI. Can shark resources be harvested sustainably? A question revisited with a review of shark fisheries. Marine Freshwater Research. 1998;49(7):553-572.

8. Clarke SC, McAllister MK, Milner-Gulland EJ, et al. Global estimates of shark catches using trade records from commercial markets. Ecol Lett. 2006;9(10):1115-1126.

9. Worm B, Davis B, Kettemer L, et al. Global catch rates, exploitation rates, and rebuilding options for sharks. Marine Policy. 2013;40:194 204.

10. Stevens JD, Bonfil R, Dulvy NK, et al. The effects of fishing on sharks, rays, and chimaeras (chondrichthyans), and the implications for marine eco-systems. ICES Journal of Marine Science. 2000;57:476-494.

11. Anderson ED. Fishery models as applied to elasmobranch fisheries. In: HL Pratt, SH Gruber \& TS Taniuchi (Eds.), Elasmobranchs as Living Resources: Advances in the Biology, Ecology, Systematics, and the Status of Fisheries. NOAA Technical Report NMFS. 1990;90:473-484.

12. Dulvy NK, Baum JK, Clarke S, et al. You can swim but you can't hide: the global status and conservation of oceanic pelagic sharks and rays. Aquatic Conservation: Marine and Freshwater Ecosystems. 2008; 18:459-482.

13. Baum JK, Myers A. Shifting baselines and the decline of pelagic sharks in the Gulf of Mexico. Ecology Letters. 2004;7:135-45.

14. Last PR, Stevens JD. Sharks and Rays of Australia, CSIRO Australia. 1994.

15. Francis MP. New Zealand shark fisheries: development, size and management. Marine and Freshwater Research. 1998;49:579-591.

16. Sant G, Hayes E. The Oceania region's harvest, trade and management of sharks and other cartilaginous fish: an overview. The World Trade in Sharks: a Compendium of TRAFFIC's Regional Studies. 1996;2:639806.
17. Zeeberg J, Corten A, de Graaf E. Bycatch and release of pelagic megafauna in industrial trawler fisheries off Northwest Africa. Fisheries Research. 2006;76(2-3):186-195.

18. Clarke S, Milner-Gulland EJ, Bjrndal T. Social, economic and regulatory drivers of the shark fin trade. Marine Resource Economics. 2007;22:305-327.

19. Clarke SC. Understanding pressures on fishery resources through trade statistics: a pilot study of four products in the Chinese dried seafood market. Fish \& Fisheries. 2004;5(1):53-74.

20. Sumpton WD, Taylor SM, Gribble NA, et al. Gear selectivity of largemesh nets and drumlines used to catch sharks in the Queensland Shark Control Program. African Journal of Marine Science. 2011;33(1):37-43.

21. Cliff G, Dudley SFJ. Reducing the environmental impact of sharkcontrol programs: a case study from KwaZulu-Natal, South Africa. Marine and Freshwater Research. 2011;62:700-709.

22. Krogh M, Reid D. Bycatch in the protective shark meshing programme off South-Eastern New South Wales, Australia. Biological Conservation. 1996;77:219-226.

23. Paterson RA. Effects of long-term anti-shark measures on target and non-target species in Queensland, Australia', Biological Conservation. 1990;52:147-159.

24. Holden MJ. Elasmobranchs In: Fish Population Dynamics JA Gulland (Ed), John Wiley \& Sons, USA. 1977;pp.187-215.

25. Meeuwig JJ, Ferreira LC. Moving beyond lethal programs for shark hazard mitigation. Animal Conservation. 2014;17(4):297-298.

26. Hazin FHV, Afonso AS. A green strategy for shark attack mitigation off Recife, Brazil. Animal Conservation. 2014;17(4):287-296.

27. Lucifora LO, Garcia VB, Worm B. Global diversity hotspots and conservation priorities for sharks', PLoS One. 2011;6(5):e19356.

28. Herndon A, Gallucci VF, DeMaster D, et al. The case for an international Commission for the Conservation and Management of Sharks (ICCMS). Marine Policy. 2010;34(6):1239-1248.

29. Godin AC, Worm B. Keeping the lead: how to strengthen shark conservation and management policies in Canada. Marine Policy. 2010;34(5):995-1001.

30. Sala A, Lucchetti A, Affronte M. Effects of turtle excluder devices on bycatch and discard reduction in the demersal fisheries of Mediterranean Sea. Aquatic Living Resources. 2011;24(2):183-192.

31. Anderson I \&Gronstal M. Jaws of life: developing international shark finning regulations through lessons learned from the International Whaling Commission. Transnational Law \& Contemporary Problems. 2011;20(2):174-189.

32. Gribble NA, McPherson G, Lane B. Effect of the Queensland Shark Control, Program on non-target species: whale, dugong, turtle and dolphin: a review. Marine and Freshwater Research. 199849(7):645651 